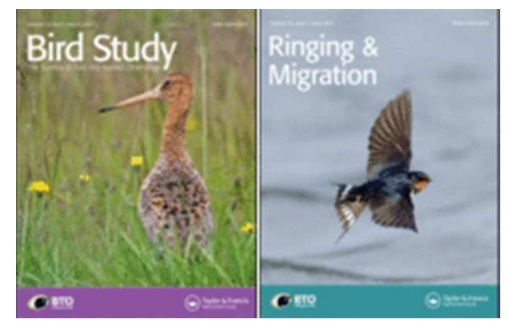

\title{
Vegetation structure influences foraging decisions in a declining grassland bird: the importance of fine scale habitat and grazing regime
}

\begin{tabular}{|r|l|}
\hline Journal: & Bird Study/Ringing \& Migration \\
\hline Manuscript ID & BS-2015-116.R2 \\
\hline Danuscript Type: & Original Article \\
\hline Complete List of Authors: & $\begin{array}{l}\text { Murray, Christopher; University of Stirling, Biological \& Environmental } \\
\text { Sciences } \\
\text { Minderman, Jeroen; University of St. Andrews, School of Biology } \\
\text { Allison, James; Scottish Wildlife Trust, } \\
\text { Calladine, John; British Trust for Ornithology (Scotland), }\end{array}$ \\
\hline Keywords: & Whinchat, Breeding ecology, marginal upland, foraging behaviour, grazing \\
\hline
\end{tabular}


1 Vegetation structure influences foraging decisions in a declining grassland bird: the 2 importance of fine scale habitat and grazing regime

4 CHRISTOPHER MURRAY $^{1 *}$, JEROEN MINDERMAN ${ }^{1,2}$, JAMES ALLISON $^{3}$ \& JOHN CALLADINE ${ }^{4}$ 5

6 *amarumayo@gmail.com

$8{ }^{1}$ Biological \& Environmental Sciences, School of Natural Sciences, University of Stirling, Stirling, FK9

9 4LA, UK; Current - 5571 Hilltop Street, Crozet, Virginia, 22932, USA; amarumayo@gmail.com

$112^{2}$ School of Biology, University of St. Andrews, St. Andrews, KY16 9TH, UK

$12{ }^{3}$ Scottish Wildlife Trust, Harbourside House, 110 Commercial Street, Edinburgh, EH6 6NF, UK

$13{ }^{4}$ British Trust for Ornithology (Scotland), School of Biological Sciences, University of Stirling, FK9 4LA, 14 UK

17 Short title: Vegetation structure and foraging Whinchats

18 Keywords: Whinchat, breeding ecology, marginal upland, foraging behaviour, grazing

\section{SUMMARY}

36 Capsule Whinchat Saxicola rubetra foraging behaviour was significantly influenced by differences in 
37 habitat structure and grazing.

39 Aims To assess how habitats selected by breeding Whinchats for foraging differed from wider territory

40 attributes in multiple marginal upland areas in Scotland under contrasting grazing management:

41 grazed principally by domestic sheep, Red Deer Cervus elaphus or ungrazed. Additionally, to identify

42 any limitations in suitable foraging areas imposed by differences in land-use.

44 Methods We compared fine-scale vegetation structure in patches chosen for foraging by Whinchats in 45 contrasting grazing management regimes.

47 Results Whinchats were less likely to forage in patches with a greater cover of bracken and tall non48 bracken vegetation, regardless of grazing regime. Grass cover influenced foraging behaviour, 49 however, only in ungrazed habitats. Here, Whinchats were less likely to forage in areas with high grass 50 cover.

51

52 Conclusion Whinchats appear to require a mosaic or range of sward structures within a breeding 53 territory, which highlights the importance of exploring the influence of vegetation structure on breeding 54 birds at different spatial scales. Our results suggest that suitable foraging patches were plentiful within 55 grazed habitats but potentially limited in ungrazed habitats. Further work is needed to identify 56 management regimes and interventions to maintain conditions suitable for breeding Whinchats that 57 are compatible with other land use and conservation objectives. 


\section{INTRODUCTION}

60 Farmland birds in Europe have undergone large population declines and range contractions over the 61 past several decades (Pain \& Pienkowski 1997, Donald et al. 2001). This has been attributed primarily 62 to the intensification of agriculture leading to widespread reductions in habitat quality and food 63 availability (Fuller et al. 1995, Siriwardena et al. 1998, Chamberlain et al. 2000, Donald et al. 2001). 64 The majority of agricultural land in Britain is grassland (McGilloway 2005). Changes in management 65 notably increased fertilizer loads and, where applicable, changes in cutting regimes such as more 66 frequent and earlier mowing and increased silage production - have altered the habitat by reducing 67 vegetation complexity and heterogeneity (Vickery et al. 2001). This has rendered these habitats less 68 suitable for breeding birds (Donald et al. 2001, Vickery et al. 2001). Certain species have retreated to 69 upland and marginal upland areas where agricultural intensification has tended to be less severe and 70 suitable conditions likely remain (Archaux 2007, Calladine \& Bray 2012). These marginal uplands 71 areas describe the indistinct and often variable boundary between the 'true' uplands, an area of 72 relatively high altitude and exposure where agriculture is restricted to low intensity grazing, and lower

73 or less exposed land where more intensive agricultural practices have proven to be economically 74 viable.

76 One such grassland species which was formerly widespread across lowland Europe but has recently 77 declined is the Whinchat Saxicola rubetra (Bastian et al. 1997, Broyer 2009, Harris et al. 2014). 78 Changes in meadow management practices, in particular earlier mowing dates and reductions in 79 vegetation complexity and habitat heterogeneity leading to reduced availability of arthropod prey, have 80 been suggested as likely drivers in mainland Europe (Müller et al. 2005, Britschgi et al. 2006, Fischer 81 et al. 2013). As an Afro-Palearctic migrant, the Whinchat also faces pressures both during migration 82 and on their wintering grounds, which could be contributing to their declines. However, studies report 83 evidence of favourable conditions from a wintering location in Nigeria, possibly shifting the focus of 84 declines away from these areas (Hulme \& Cresswell 2012, Blackburn \& Cresswell 2015). In Britain, 85 severe, accelerating, long-term declines have become widespread, and now affect historic stronghold 86 areas for the species (Henderson et al. 2014). Overall, breeding populations have declined in 87 abundance by 55\% since 1995 (Harris et al. 2014). Following a 40\% range contraction since 1970 in 88 Britain (Balmer et al. 2013), the species is now largely associated with less intensively managed 89 pasture (including moorland) in the uplands and marginal uplands (Henderson et al. 2004, Fuller et al. 90 2006, Calladine \& Bray 2012, Balmer et al. 2013). This provides an interesting example of a species 91 impacted by 'altitudinal squeezing' where the population is apparently limited at lower altitudes by 92 intensive agricultural management and at higher altitudes by environmental constraints upon its 93 breeding biology (Calladine \& Bray 2012). Consequently, land management decisions within this 
94 'narrow belt', where suitable conditions remain, will be of critical importance for the remaining

95 populations of Whinchats as even within this remaining stronghold, declines have become widespread

96 (Henderson et al. 2014).

98 In agricultural areas, grassland vegetation structure can influence bird ecology in many ways (Benton

99 et al. 2003). A reduction in vegetation complexity and heterogeneity can reduce arthropod richness

100 and abundance (Dennis et al. 1998, Dennis et al. 2005, Morris 2000), which in turn can influence

101 breeding productivity and survival through foraging and chick provisioning (Andersson 1981, Verboven

102 \& Visser 1998). Adults provisioning young typically need resource rich foraging patches (Morris et al.

103 2002, Benton et al. 2003). Such patches may be less abundant in lower quality habitats, which may

104 act to increase provisioning distances or reduce provisioning rates, leading to unsustainable energy

105 budgets, poorer body condition of chicks and adults, and ultimately, lower reproductive success

106 (Andersson 1981, Martin 1987, Hinam \& Clair 2008). Additionally, vegetation structure can alter

107 predation risk and nesting site availability (Lima \& Dill 1990, Benton et al. 2003). For example,

108 vegetation can obscure predators and prey from each other, provide cover and assist in camouflaging

109 nesting sites (Whittingham \& Evans 2004), all of which can influence reproductive success. The extent

110 to which agriculture impacts habitat and vegetation structure, and therefore its influence on breeding

111 birds, varies according to land use practices (Vickery et al. 2001). Within managed pasture, lower

112 intensity land-use practices, which minimize disturbance to vegetation structure, may assist in the

113 preservation of key habitat features required by breeding birds, such as low to moderate grazing,

114 which aids the formation of complex vegetation mosaics and restricts succession (Vickery et al. 2001,

115 Evans et al. 2006, Dennis et al. 2008). Such practices are common in marginal upland areas, since

116 these areas tend to include some of the most extensive 'low-intensity' agriculture largely due to

117 combinations of relative remoteness, inaccessibility for large mechanized equipment and the relatively

118 small (compared to more productive lowlands) returns for agricultural intensification. As such, marginal

119 upland areas can retain suitable conditions for a suite of breeding birds as 'high nature value'

120 farmland, which may serve as potential refuges for declining species such as Whinchats (Archaux

121 2007, Calladine \& Bray 2012). Conservation practices would benefit from a better understanding of the

122 role agriculture plays in maintaining high nature value farmland (Fuller \& Gough 1999, Evans et al.

123 2006).

125 Changes in Whinchat breeding abundance within marginal upland areas appear to be spatially non126 random, suggesting a general redistribution towards more favoured habitats, however, the overall 127 trend has been for a continued decline (Henderson et al. 2014). Furthermore, recent habitat 128 assessments of breeding territories within a favourable marginal upland area have failed to identity 129 predictors of occupancy at the territory level other than altitude and aspect, both measures of 
130 environmental exposure (e.g. Calladine \& Bray 2012). This suggests that limitations could operate at a 131 finer scale. In this study we therefore assessed within-territory selection of foraging patches by 132 Whinchats breeding within contrasting marginal upland habitats in Scotland. These included areas 133 predominantly grazed by sheep, Red Deer Cervus elaphus and areas where grazing had been 134 excluded. Specifically, we asked: 1) For Whinchats breeding in marginal upland areas, does fine-scale 135 vegetation structure (type, height and cover) affect forage patch selection and, if so, which features 136 are important? 2) Are these features the same in areas with contrasting grazing regimes?

137 By comparing what features, if any, are important for foraging by breeding Whinchats and their 138 availability within territories in areas of contrasting land use, we expect to find common attributes that 139 are used within different areas and therefore identify important features for foraging Whinchats. 140 Identification of how any suitable foraging areas might be limited by differences in land use could 141 inform conservation management to improve the status of Whinchats in upland pastoral environments.

\section{MATERIALS \& METHODS}

\section{Study area}

146 This study was conducted in 2014 from May to July. Five sites were selected in contrasting marginal 147 upland areas under different grazing managements in central and northern Scotland (Fig. 1). Menstrie 148 Glen ( $56^{\circ} 09^{\prime} \mathrm{N}, 3^{\circ} 51^{\prime} \mathrm{W} ; 150$ - $300 \mathrm{~m}$ above sea level) and Glen Quey (56 $13^{\circ} \mathrm{N}, 3^{\circ} 39^{\prime} \mathrm{W} ; 225$ $149600 \mathrm{~m}$ above sea level) represent areas of current and former upland hill pasture respectively, which 150 consist of grasses with distinct areas of Common Bracken Pteridium aquilinum, Rush Juncus spp., 151 herbaceous plants such as Common Nettle Urtica dioica, Foxglove Digitalis purpurea and Thistle 152 Asteraceae spp. and limited ericaceous cover, primarily Heather Calluna vulgaris and Bilberry 153 Vaccinium myrtillus. Domestic grazing animals have been excluded from Glen Quey since 11 to 12 154 years prior this study. The area was planted with a mix of native broad-leaf tree species that have now 155 grown to a height of approximately 5-10m. Menstrie Glen was extensively grazed by domestic sheep 156 at the time of this study. Other relevant browsing animals include Roe Deer Capreolus capreolus 157 which occur in both areas at low densities. In addition to these central sites, three discrete areas in 158 northern Scotland were chosen (Strath Oykel $57^{\circ} 53^{\prime} \mathrm{N} 4^{\circ} 35^{\prime} \mathrm{W}$; Strath Brora $58^{\circ} 04^{\prime} \mathrm{N} 4^{\circ} 02^{\prime} \mathrm{W}^{\prime}$; 159 Strath Naver $58^{\circ} 21^{\prime} \mathrm{N} 4^{\circ} 15^{\prime} \mathrm{W}$, all $30-120 \mathrm{~m}$ above sea level), all of which are linear valley bottoms 160 no wider than approximately $500 \mathrm{~m}$ in most places. These valley bottoms are comprised of either 161 enclosed, agriculturally improved pasture or extensive semi-natural rough grassland with isolated 162 fragments of semi-natural woodland and scrub. The surrounding habitats consist of extensive 163 moorland (rough grasses and ericaceous vegetation), plantations of predominantly coniferous trees 164 (some of which had been clear-felled) with some smaller areas of broad-leaf tree planting. The 165 enclosed pastures are grazed mostly by domestic sheep and moorland areas more extensively by 
166 both domestic sheep and relatively high densities of wild Red and Roe Deer. Plantations and other wooded patches are specifically fenced to exclude large herbivores.

\section{Location and description of forage patches}

170 A total of 59 territories where Whinchat young were being provisioned were located including: 20 171 territories at Menstrie Glen, 18 at Glen Quey, 11 at Strath Brora, nine at Strath Naver and one at Strath 172 Oykell. Territories were identified by clustered locations of birds through the season and by 173 simultaneous observations of different birds (Bibby et al. 2000). Our aim was to assess any 174 differences in vegetation composition and structure between areas where Whinchats successfully

175 foraged and the wider habitat within, or very close to, the breeding territory. Feeding Whinchats were 176 watched to identify areas used for foraging in order to take measurements to describe the vegetation 177 of those patches. For the purposes of this study, we defined a forage patch as the exact area (or very 178 close to it) where a bird was seen to collect food that was then swallowed or carried to a nest or to 179 recently fledged young (which tended to stay within the breeding territories). Locating patches was 180 accomplished by observing foraging birds with binoculars and/or a field telescope and by paying close 181 attention to conspicuous features in the landscape and, when necessary, making sketches to facilitate 182 locating the forage patch upon approach. At the location of each foraging patch, attributes of 183 vegetation structure were sampled by placing $1 \mathrm{~m}^{2}$ quadrats and estimating the percent cover in each 184 of three height categories $(0-20 \mathrm{~cm}, 20-50 \mathrm{~cm}$, and 50-100 cm) of: (1) bracken and other ferns, (2) 185 grasses and sedges (graminoids), (3) rushes, (4) non-grassy herbaceous vegetation (forbs) and, (5) 186 ericaceous vegetation (such as Heather and Bilberry). Ground cover of: (1) mosses and lichens and, 187 (2) bare ground was also estimated. In patches where the adult bird was seen to forage in an area 188 large enough for more than one quadrat sample to be taken, up to four quadrats were randomly 189 placed within an area of homogenous vegetation by moving the grid $1 \mathrm{~m}$ in a random compass 190 direction (achieved by spinning the compass wheel without looking). For each quadrat within each 191 sampled patch, two reference patches located $10 \mathrm{~m}$ to the north and $10 \mathrm{~m}$ to the south, were sampled 192 using an identical approach and number of quadrats. This 2:1 ratio in reference to forage quadrats 193 was consistent across management regimes.

\section{Statistical Analyses}

196 All analyses were carried out in R version 3.0.2 (R Development Core Team 2013, Crawley 2012). We 197 conducted principle component analyses (PCA) of the measures of habitat structure within the forage 198 and reference patches to reduce the dimensionality of our data to a smaller number of linear 199 combinations. This allowed us to avoid (1) multicollinearity in subsequent models as well as (2) 200 inferred and arbitrary decisions about which habitat measures to include (Peres-Neto et al. 2005). For 201 our PCA we included the nine variables that were represented in at least $10 \%$ of the surveyed 
202 quadrats from the original forage and reference patch habitat datasets (Table 1). These were chosen 203 because the remaining 10 measured habitat features were deemed too scarce to be effectively 204 analysed and were likely not representative of the overall habitat. Factor loadings greater than 0.3 205 were considered to load significantly onto the component (after e.g. Minderman et al. 2009). Principle 206 components were retained for further analysis where axes eigenvalues were greater than 1.0 (the 207 Kaiser criteria; Yeomans \& Golder 1982).

To assess the associations between habitat metrics (the PCA scores) and the probability of a patch 210 being used for foraging by Whinchats, we fitted a generalized linear mixed-effects model (GLMM) 211 specifying a binomial error distribution and logit link function (logistic regression) with the 'glmer' 212 function in the R package Ime4 (v. 1.0-6; Bates et al. 2014). In 18 quadrats (4 patches; the single 213 territory from the Strath Oykell study site) the management regime was undetermined and so these 214 data were only included in the PCA and excluded from the main analysis. Random terms were 215 included in our model to account for the variation inherent across different study sites and amongst 216 individual foraging patches where repeated measures occurred (Bolker et. al. 2009). For our maximal 217 model, the dependent variable was 'patch type' (binary; 1 for a patch used by a foraging bird and 0 for 218 a reference patch). Possible predictor variables were the PCA-derived habitat metrics (PC scores; 219 Table 2) with eigenvalues $>1$. Additionally, in order to ask whether the effect of vegetation structure on 220 the probability of a patch being foraged or not is dependent upon the management regime we included 221 the interaction between each derived habitat metric and the three-level categorical 'management 222 regime' variable (sheep-grazed, deer grazed or ungrazed). The number of days elapsed since the 223 beginning of the study was also included as an additional fixed covariate. Random variables included 224 in the model were 'patch identity' (each with a minimum separation distance of $5 \mathrm{~m}$ ) nested within 225 'study site'. Prediction plots were created by plotting the raw data with lines fitted from the regression 226 predictions of the final model. Confidence limits were obtained via simulation ( $\mathrm{n}=1000$ simulations) at 227 estimated parameter values using the 'sim' function in the R package arm (v. 1.7-07, Gelman et al. 228 2014). The full model was simplified to a minimum adequate model using Likelihood Ratio Tests 229 (Sokal \& Rohlf 1995), with the exception of 'Julian day' which was left in the model as a control 230 variable to account for the expected change in habitat variables over time (seasonal growth of 231 vegetation). Likelihood ratio tests represent a robust method for model simplification and are generally 232 appropriate for inference on random factors (Bolker et al. 2009). We confirmed that all candidate final 233 models adequately met model assumptions, and were not excessively over or under dispersed 234 (Crawley 2012).

235

\section{RESULTS}




\section{Vegetation metrics}

239 In total we sampled 1532 quadrats from 307 distinct foraging patches from our five study sites (Table

240 1). Within these territories, 1049 quadrats (from 170 patches) were sampled in areas where the 241 dominant management regime was grazing by sheep, 127 quadrats (from 36 patches) in habitats where wild deer grazing represented the dominant management, 338 quadrats (from 97 patches) in habitats where domestic and wild grazing were largely excluded by fencing supplemented by active

244 monitoring and removal of incidental grazing intruders.

245 A PCA of habitat measures yielded 3 axes with eigenvalues > 1.0 (Table 2): First axis (PC1, 246 accounting for $30.1 \%$ of the total variation) - Represents an index of bracken cover at all three height 247 levels. A high PC1 score indicates greater cover with bracken; Second axis (PC2, accounting for $24821.2 \%$ of the total variation) - Represents an index of grass cover at all three height levels. A high PC2 249 score indicates greater cover by grasses and lower cover by herbaceous plants and mosses; Third 250 axis (PC3, accounting for $14.2 \%$ of the variation) - Represents an index of vegetation height that is not bracken. A high PC3 score represents greater cover by taller herbaceous vegetation and tall grasses with lower ground cover by mosses. In our study sites this likely represents tall rank grasses, Nettle, Foxglove, Thistle or Rosebay Willowherb (Fireweed) Chamerion angustifolium.

\section{Forage patch selection}

256 The probability of a patch being used for foraging was significantly affected by differences in habitat 257 structure and grazing regime (Table 3). Areas with a greater cover of bracken (PC1) were used less 258 frequently for foraging, as shown by the negative association between the probability of a patch being 259 used for foraging and PC1 (Fig. 2). Additionally, patches containing a greater cover of tall vegetation 260 (combined with a lower cover of mosses and lichens; PC3) were used less frequently for foraging, 261 evident from the negative relationship between probability of a patch being used for foraging and PC3 262 (Fig. 3). These negative trends were similar across all three management regimes for both PC1 and PC3, as shown by the lack of a significant interaction of management regime with PC1 or PC3 in our model (Table 3). Fine-scale habitat structure also influenced foraging in patches containing a greater cover of grass and a lower cover of herbaceous plants and mosses (PC2), however, this varied depending upon the grazing regime (Fig. 4). In ungrazed habitats, the probability of a patch being used for foraging was lower for patches with higher PC2 scores (more grass, and less herbaceous plant cover, which was indicative of taller swards). By contrast, in grazed habitats this pattern was reversed; patches with more grass and less herbaceous plant cover (higher PC2 scores) were more likely to be selected. This can be seen from both the significant interaction of management regime and

271 the negative association between probability of a patch being used for foraging and PC2 in ungrazed

272 habitats compared to the non-significant relationship in both deer and sheep-grazed habitats. 


\section{DISCUSSION}

\section{Forage patch attributes}

277 This study provides clear evidence that fine-scale vegetation structure within territories influences the

278 foraging behaviour of Whinchats breeding in marginal upland areas. Furthermore, the influence of 279 some habitat characteristics differed according to management regime, suggesting that prescribed 280 land management practices can influence Whinchat ecology by affecting the availability of some of the 281 fine-scale habitats that they use for foraging.

282

283 In all management regimes, Whinchats typically foraged in patches with lower bracken cover 284 compared to reference patches. Likely, this is because bracken cover influences food availability for 285 species foraging in open areas. Dense bracken represents a homogeneous habitat that is associated 286 with lower arthropod richness and abundance (Dennis et al. 1998, 2005), and greater cover probably 287 obscures prey on the ground. Foraging opportunities are therefore expected to be lower in such 288 habitats for species that require open areas to forage and those that typically seek out resource rich 289 patches, of which Whinchats are a typical example (Morris et al. 2002, Benton et al. 2003, Richter \& 290 Düttmann 2004). Similarly, in all management regimes, Whinchats foraged in patches where the sward 291 height was relatively short, and avoided tall herbaceous vegetation (mainly thistle, foxglove, nettle, 292 and willowherb), grasses and bracken; features that may limit foraging opportunities for the same 293 reasons as above. At lower cover, these features likely increase the vertical and horizontal structural 294 complexity of forage patches and provide the high vegetation diversity that has been shown to be 295 beneficial for grassland birds (Schaub et al. 2010), the perching structures important for effective 296 foraging (Oppenman 1990, Bastian \& Bastian 1997, Fischer et al. 2013) and probably support higher 297 arthropod diversity and abundance (Dennis et al. 1998). Accordingly, the vast majority of sampled 298 forage patches had at least some herbaceous vegetation and only rarely consisted of purely open 299 grassy areas, and we often observed Whinchats perching on individual herbaceous plants and 300 bracken stalks when foraging.

302 Our results suggest that suitable foraging patches are plentiful within grazed habitats but potentially 303 limited in ungrazed habitats. In these ungrazed habitats, the index describing the gradient of 304 herbaceous plants to grass cover (PC2) had a strong negative effect on foraging patch selection, so 305 that areas composed predominantly of grasses were less likely to be used for foraging compared to 306 those composed of short herbs (typically Gallium saxatile and Potentilla erecta) and mosses. By 307 contrast, in grazed habitats this pattern was either absent (in sheep grazed areas) or reversed (in deer 308 grazed areas and in both cases non-significant (possibly an artefact of relatively small sample size for 309 deer grazed areas). The fact that Whinchats specifically sought out preferred areas for foraging whilst 
310 avoiding the habitat at the wider territory scale suggests that such favourable areas may be limited,

311 especially when compared to grazed areas. In these areas, suitable foraging patches appear to be

312 more widely available since birds did not seek them out, but rather foraged freely throughout the

313 territory. Most likely, the exclusion of grazing animals allows taller swards to develop more extensively

314 resulting in reduced food availability and rendering them less suitable for foraging for the same

315 reasons that dense bracken and herbaceous vegetation are also unsuitable for foraging (see above).

316 In contrast, low-level grazing both creates and maintains complex vegetation mosaics and restricts the

317 succession of less favourable vegetation (Vickery et al. 2001). For example, lowered sward height due

318 to grazing has been shown to increase prey availability and influence the foraging behaviour of many

319 grassland birds (Milsom et al. 1998, Evans et al. 2006). In our study, foraging patches in ungrazed

320 habitats contained on average more short herbaceous vegetation and mosses (as opposed to areas of

321 tall grasses), further supporting a preference for areas with higher vegetation diversity.

323 Conservation implications

324 Our study highlights the importance of exploring the influence of vegetation structure on breeding birds 325 at different spatial scales (e.g. Johnson 1980). Landscape-scale studies link Whinchats to open, non326 forested areas (Suter 1988), and territory-scale studies show associations with relatively tall 327 vegetation, which in pastoral areas particularly includes bracken (Stillman \& Brown 1994, Britschgi et 328 al. 2006, Pearce-Higgins \& Grant 2006). To satisfy all requirements for breeding Whinchats, there is a 329 need for taller swards (for song posts, nest cover and predator avoidance; Greig-Smith 1982, Fischer 330 et al. 2013) as well as short swards for efficient foraging (this study). These vegetation mosaics need 331 to be present within an area of a Whinchat's breeding territory, which is typically less than 1 ha 332 (Calladine \& Bray 2012). Within our study areas, taller swards mostly consisted of bracken as well as 333 some tall grass and herbaceous species, which created stands that approached or were greater than $334100 \mathrm{~cm}$ throughout the breeding season. Shorter swards, which were favoured by Whinchats for 335 foraging typically included grasses, herbs and mosses in areas generally less than $20 \mathrm{~cm}$ in height.

337 Low-intensity and uneven grazing is likely to create and maintain the vegetation mosaics and perching 338 structures (Crofts \& Jefferson 1999, Evans et al. 2006) that are required within Whinchat breeding 339 territories. The modification of grazing regimes can sometimes successfully achieve conservation aims 340 (Ward et al. 1995, Evans et al. 2006, Calladine et al. 2002). Further work is needed to identify the 341 management regimes and interventions that are required to maintain a mosaic of sward structures that 342 is suitable for breeding Whinchats and that is compatible with other land uses and conservation 343 objectives. Our study suggests that both sheep and deer grazed regimes can provide such conditions 344 but the roles of spatial, seasonal and long term variations and changes in grazing intensities deserves 345 further attention. 


\section{ACKNOWLEDGEMENTS}

348

349 We are grateful to the Sound Approach for funding to support this study, the British Trust for 350 Ornithology (BTO) for providing a BTO Research Grant and to the Woodland Trust and Tillhill 351 Forestry Limited for access to study areas. Additional fieldwork was undertaken by James Bray, 352 Susan Holoran, Emma Blackburn, Sofia Motta E. Pralon, Thomas Plant and John McTague. 353 This study complies with the current ethic regulations of the United Kingdom and the University 354 of Stirling department of Biological \& Environmental Sciences. 


\title{
REFERENCES
}

356

Andersson, M. 1981. Central place foraging in the Whinchat, (Saxicola rubetra). Ecology 62: 538-544.

359

360

Archaux, F. 2007. Are mountains refuges for farmland bird species? A case study in the northern French Alps. Bird Study 54: 73-79.

362

363

Balmer, D., Gillings, S., Caffrey, B., Swann, B., Downie, I. \& Fuller, R. 2013. Bird Atlas 2007364 11: The breeding and wintering birds of Britain and Ireland. BTO, Thetford.

365

Bastian, H.V., Bastian, A., Bocca, M., \& Suter, W. 1997. Whinchat (Saxicola rubetra). In Hagemeijer, W. J. M. \& Blair, M. J. (eds) The EBCC Atlas of European Breeding Birds: Their Distribution and Abundance, 526-527. Poyser, London.

Benton, T.G., Vickery, J.A. \& Wilson, J.D. 2003. Farmland biodiversity: Is habitat 376

Bates, D., Maechler, M., Bolker, B. \& Walker, S. 2014. Ime4: Linear mixed-effects models using Eigen and S4. R package version 1.1-7. http://CRAN.R-project.org/package=Ime4. Accessed 18 Aug 2015.

\author{
heterogeneity the key? Trends. Ecol. Evol. 18: 182-188.
}

Bibby, C.J., Philips, B.N., Hill, D.A. \& Mustoe, S. 2000. Bird Census Techniques. Academic Press, London.

Blackburn, E. \& Cresswell, W. 2015. High within-winter and annual survival for a declining Palearctic migrant: evidence that wintering conditions may not limit migrant populations. Ibis. In press.

Bolker, B.M., Brooks, M.E., Clark, C.J., Geange, S.W., Poulsen, J.R., Stevens, M.H.H. \& White J.S.S. 2009. Generalized linear mixed models: a practical guide for ecology and evolution. Trends. Ecol. Evol. 24: 127-135. 
Britschgi. A., Spaar, R. \& Arlettaz, R. 2006. Impact of grassland farming intensification on the breeding ecology of an indicator insectivorous passerine, the Whinchat Saxicola rubetra: Lessons for overall alpine meadowland management. Biol. Conserv. 130: 193-205.

Broyer, J. 2009. Whinchat Saxicola rubetra reproductive success according to hay cutting schedule and meadow passerine density in alluvial and upland meadows in France. J. Nat. Conserv. 17: 160-167.

Calladine, J., Baines, D. \& Warren, P. 2002. Effects of reduced grazing on population density and breeding success of black grouse in northern England. J. Appl. Ecol. 39: 772-780.

Calladine, J. \& Bray, J. 2012. The importance of altitude and aspect for breeding Whinchats Saxicola rubetra in the uplands: Limitations of the uplands as a refuge for a declining, formerly widespread species? Bird Study 59: 43-51.

Chamberlain, D., Fuller, R., Bunce, R., Duckworth, J. \& Shrubb, M. 2000. Changes in the abundance of farmland birds in relation to the timing of agricultural intensification in England and Wales. J. Appl. Ecol. 37: 771-788.

Crawley, M.J. 2012. The R book. John Wiley \& Sons, Chichester.

Crofts, A. \& Jefferson, R.G. 1999. The Lowland Grassland Management Handbook. English Nature, Peterborough.

Dennis, P., Young, M. \& Gordon, I. 1998. Distribution and abundance of small insects and arachnids in relation to structural heterogeneity of grazed, indigenous grasslands. Ecol. Entomol. 23: 253-264.

Dennis, P., Elston, D., Evans, D.M., Evans, S.A., Gordon, I.J., Grant, M. \& Bryant, D. 2005. Effects of grazing management on upland bird populations: disentangling habitat structure and arthropod food supply at appropriate spatial scales (GRUB). Final report to the Scottish Executive Environment and Rural Affairs Department, Edinburgh. 
Dennis, P., Skartveit, J., McCracken, D.I., Pakeman, R.J., Beaton, K., Kunaver, A. \& Evans, D.M. 2008. The effects of livestock grazing on foliar arthropods associated with bird diet in upland grasslands of Scotland. J. Appl. Ecol. 45: 279-287.

Donald, P., Green, R. \& Heath, M. 2001. Agricultural intensification and the collapse of 427 Europe's farmland bird populations. P. Roy. Soc. Lond. B. Bio. 268: 25-29.

\section{1}

432

433

434

435

436

437

438

439

Evans, D.M., Redpath, S.M., Evans, S.A., Elston, D.A., Gardner, C.J., Dennis, P. \& Pakeman, R.J. 2006. Low intensity, mixed livestock grazing improves the breeding abundance of a common insectivorous passerine. Biol. Letters 2: 636-638.

Fischer, K., Busch, R., Fahl, G., Kunz, M. \& Knopf, M. 2013. Habitat preferences and breeding success of Whinchats Saxicola rubetra in the Westerwald mountain range. $J$. Ornithol. 154: 339-349.

Fuller, R.J. \& Gough, S.J. 1999. Changes in sheep numbers in Britain: implications for bird populations. Biol. Conserv. 91: 73-89.

Fuller, R., Gregory, R., Gibbons, D., Marchant, J., Wilson, J., Baillie, S. \& Carter, N. 1995.

Population declines and range contractions among lowland farmland birds in Britain. Conserv. Biol. 9: 1425-1441.

Fuller, R.J., Atkinson, P.W., Garnett, M.C., Conway, G.J., Bibby, C.J. \& Johnstone, I.G. 2006. Breeding bird communities in the upland margins (ffridd) of Wales in the mid-1980s. Bird Study 53: 177-186.

Gelman, A. \& Su, Y. 2014. Arm: Data Analysis Using Regression and Multilevel/Hierarchical Models. R package version 1.7-07. http://CRAN.R-project.org/package=arm. Accessed 18 Aug 2015

Gillings, S., Fuller, R.J. \& Balmer, D.E. 2000. Breeding birds in scrub in the Scottish highlands: variation in community composition between scrub type and successional stage. Scottish Forestry 54: 73-85. 
Grant, M.C. \& Pearce-Higgins, J.W. 2012. Spatial variation and habitat relationships in moorland bird assemblages: a British perspective. In Fuller, R.J. (ed.) Birds and Habitat: relationships in changing landscapes, 1st edn: 207-236. Cambridge University Press, Cambridge.

459

Greig-Smith, P.W. 1982. Dispersal between nest-sites by stonechats Saxicola torquata in relation to previous breeding success. Ornis. Scand. 13: 232-238.

462 D.G., Procter, D. \& Baillie, S.R. 2014. The Breeding Bird Survey 2013. BTO Research Report 638, British Trust for Ornithology, Thetford.

Henderson, I.G., Fuller, R.J., Conway, G.J.\& Gough, S.J. 2004. Evidence for declines in populations of grassland-associated birds in marginal upland areas of Britain. Bird Study 51: 12-19.

470

Henderson, I., Calladine, J., Massimino, D., Taylor, J.A. \& Gillings, S. 2014. Evidence for contrasting causes of population change in two closely related, sympatric breeding species the Whinchat Saxicola rubetra and Stonechat Saxicola torquata in Britain. Bird Study 61: 553-565.

475

Hinam, H.L. \& Clair, C.C.S. 2008. High levels of habitat loss and fragmentation limit reproductive success by reducing home range size and provisioning rates of northern sawwhet owls. Biol. Conserv. 141: 524-535.

Hulme, M.F. \& Cresswell, W. 2012. Density and behaviour of Whinchats Saxicola rubetra on African farmland suggest that winter habitat conditions do not limit European breeding

Johnson, D. H. 1980. The comparison of usage and availability measurements for evaluating 485 resource preference. Ecology 61: 65-71. 
487

488

489

490

491

492

493

494

495

496

497

498

499

500

501

502

503

504

505

506

507

508

509

510

511

512

513

514

515

516

517

518

Lima, S.L. \& Dill, L.M. 1990. Behavioral decisions made under the risk of predation: A review and prospectus. Can. J. Zoolog. 68: 619-640.

Martin, T.E. 1987. Food as a limit on breeding birds: a life-history perspective. Annu. Rev. Ecol. Syst. 18: 453-487.

Milsom, T.P., Ennis, D.C., Haskell, D.J., Langton, S.D. \& McKay, H.V. 1998. Design of grassland feeding areas for waders during winter: the relative importance of sward, landscape factors and human disturbance. Biol. Conserv. 84: 119-129.

McGilloway, David A. 2005. Grassland: a global resource. Wageningen Academic Publishers. Wageningen.

Minderman, J., Reid, J.M., Evans, P.G. \& Whittingham, M.J. 2009. Personality traits in wild starlings: Exploration behavior and environmental sensitivity. Behav. Ecol. 67: 1-8.

Morris, A., Bradbury, R. \& Wilson, J. 2002. Determinants of patch selection by Yellowhammers Emberiza citrinella foraging in cereal crops. Asp. Appl. Biol. 67: 43-50.

Morris, M. 2000. The effects of structure and its dynamics on the ecology and conservation of arthropods in British grasslands. Biol. Conserv. 95: 129-142.

Müller, M., Spaar, R., Schifferli, L.\& Jenni, L. 2005. Effects of changes in farming of subalpine meadows on a grassland bird, the Whinchat Saxicola rubetra. J. Ornithol. 146: 14-23.

Oppermann, R. 1990. Suitability of different vegetation structure types as habitat for the Whinchat Saxicola rubetra. Vegetatio 90: 109-116.

Pain, D.J. \& Pienkowski, M.W. 1997. Farming and birds in Europe: The Common Agricultural Policy and its implications for bird conservation. Academic Press, Waltham.

Pearce-Higgins, J.W. \& Grant, M.C. 2006 Relationships between bird abundance and the 
composition and structure of moorland vegetation. Bird Study 53: 112-125.

520

Peres-Neto, P.R., Jackson, D.A. \& Somers, K.M. 2005. How many principal components? stopping rules for determining the number of non-trivial axes revisited. Comput. Stat. Data An. 49: 974-997.

R Core Development Team. 2013. R: A language and environment for statistical computing.

Richter, M. \& Düttmann, H. 2004. Die Bedeutung von Randstrukturen für den Nahrungserwerb des Braunkehlchens Saxicola rubetra in Grünlandgebieten der Dümmerniederung [The importance of ecotones as feeding habitats for grassland-breeding Whinchats in Western Lower Saxony]. Vogelwelt 125: 89-98.

531

532

Schaub, M., Martinez, N., Tagmann-loset, A., Weisshaupt, N., Maurer, M.L., Reichlin,T.S., Abadi, F., Zbinden, N., Jenni, L., \& Arlettaz, R. 2010. Patches of bare ground as a staple commodity for declining ground-foraging insectivorous farmland birds. PLoS One 5: e13115.

535

Siriwardena, G.M., Baillie, S.R., Buckland, S.T., Fewster, R.M., Marchant, J.H. \& Wilson, J.D. 1998. Trends in the abundance of farmland birds: A quantitative comparison of smoothed common birds census indices. Journal of Applied Ecology 35: 24-43.

539

Sokal, R.R. \& Rohlf, F.J. 1995. Biometry: The Principles and Practice of Statistics in Biological Research. W.H. Freeman \& Co, London.

542

Stillman, R.A. \& Brown, A.F. 1994. Population sizes and habitat associations of upland breeding birds in the south Pennines, England. Biol. Conserv. 69: 307-314.

Suter, W. 1988. Whinchat Saxicola rubetra in Bauer, K.M. \& Glutz von Blotheim, U.N. (eds)

Verboven, N. \& Visser, M.E. 1998. Seasonal variation in local recruitment of Great Tits: The importance of being early. Oikos 81: 511-524. 
552 Vickery, J., Tallowin, J., Feber, R., Asteraki, E., Atkinson, P., Fuller, R. \& Brown, V.K. 2001.

553 The management of lowland neutral grasslands in Britain: Effects of agricultural practices on

554 birds and their food resources. J. Appl. Ecol. 38: 647-664.

555

556 Ward, S.D., MacDonald, A.J. \& Matthew, E.M. 1995. Scottish heaths and moorland: how

557 should conservation be taken forward? In Thompson, D.B.A., Hester, A.J. \& Usher, M.B.

558 (eds) Heaths and moorland: Cultural landscapes, 1st edn: 319-333 Her Majesty's Stationary

559 Office, Edinburgh.

560

561 Whittingham, M.J., \& Evans, K.L. 2004. The effects of habitat structure on predation risk of 562 birds in agricultural landscapes. Ibis 146: 210-220.

563

564 Yeomans, K.A. \& Golder, P.A. 1982. The Guttman-Kaiser criterion as a predictor of the number 565 of common factors. Statistician 31: 221-229. 
Table 1 Summary statistics of the raw habitat variables and the first three extracted PC axes displayed as means ( $\pm 1 \mathrm{se}$ ). For the raw habitat variables, the proportion of total quadrants in which they occurred per management regime is also provided. Variables shown in bold (those which occurred in at least $10 \%$ of the sample quadrants) were selected for analysis and included in the PCA

\begin{tabular}{|c|c|c|c|c|c|c|}
\hline \multirow{2}{*}{ Habitat Variables } & \multicolumn{2}{|c|}{$\begin{array}{c}\text { Sheep Grazed } \\
(\mathrm{n}=1049 \text { quadrats })\end{array}$} & \multicolumn{2}{|c|}{$\begin{array}{c}\text { Deer Grazed } \\
(\mathrm{n}=127 \text { quadrats) }\end{array}$} & \multicolumn{2}{|c|}{$\begin{array}{c}\text { Ungrazed } \\
(n=338 \text { quadrats }\end{array}$} \\
\hline & $\begin{array}{c}\text { Mean } \\
(\% \pm 1 \text { se })\end{array}$ & Proportion & $\begin{array}{c}\text { Mean } \\
(\% \pm 1 \text { se })\end{array}$ & Proportion & $\begin{array}{c}\text { Mean } \\
(\% \pm 1 \text { se })\end{array}$ & Proportion \\
\hline Herb. Veg. $(0-20 \mathrm{~cm})$ & $9.4 \pm 0.5$ & 0.42 & $20.4 \pm 1.7$ & 0.82 & $19.7 \pm 1.2$ & 0.69 \\
\hline Herb. Veg. $(20-50 \mathrm{~cm})$ & $4.2 \pm 0.4$ & 0.21 & $1.6 \pm 0.6$ & 0.12 & $3.9 \pm 0.8$ & 0.15 \\
\hline Herb. Veg. $(50-100 \mathrm{~cm})$ & $1.7 \pm 0.3$ & 0.08 & $0.3 \pm 0.3$ & 0.01 & $2.4 \pm 0.7$ & 0.06 \\
\hline Grasses $(0-20 \mathrm{~cm})$ & $59.0 \pm 1.2$ & 0.83 & $24.3 \pm 2.1$ & 0.77 & $61.2 \pm 1.6$ & 0.97 \\
\hline Grasses $(20-50 \mathrm{~cm})$ & $26.6 \pm 1.0$ & 0.58 & $21.1 \pm 2.1$ & 0.76 & $35.7 \pm 1.8$ & 0.88 \\
\hline Grasses $(50-100 \mathrm{~cm})$ & $4.0 \pm 0.4$ & 0.19 & $1.2 \pm 0.6$ & 0.05 & $5.7 \pm 1.0$ & 0.17 \\
\hline Rushes $(0-20 \mathrm{~cm})$ & $4.1 \pm 0.4$ & 0.11 & $0.1 \pm 0.1$ & 0.01 & $1.8 \pm 0.5$ & 0.07 \\
\hline Rushes $(20-50 \mathrm{~cm})$ & $3.8 \pm 0.4$ & 0.11 & $0.8 \pm 0.2$ & 0.09 & $1.7 \pm 0.5$ & 0.06 \\
\hline Rushes $(50-100 \mathrm{~cm})$ & $2.3 \pm 0.3$ & 0.07 & $0.7 \pm 0.3$ & 0.06 & $1.4 \pm 0.5$ & 0.04 \\
\hline Ericaceous veg. $(0-20 \mathrm{~cm})$ & $1.6 \pm 0.3$ & 0.05 & $3.7 \pm 1.1$ & 0.23 & $1.7 \pm 0.6$ & 0.04 \\
\hline Ericaceous veg. $(20-50 \mathrm{~cm})$ & $1.3 \pm 0.3$ & 0.03 & $1.1 \pm 0.4$ & 0.06 & $1.1 \pm 0.5$ & 0.01 \\
\hline Ericaceous veg. $(50-100 \mathrm{~cm})$ & $0.3 \pm 0.1$ & 0.01 & $0.0 \pm 0.0$ & 0.00 & $0.0 \pm 0.0$ & 0.00 \\
\hline Bracken $(0-20 \mathrm{~cm})$ & $9.1 \pm 0.7$ & 0.26 & $0.1 \pm 0.1$ & 0.02 & $4.3 \pm 1.0$ & 0.06 \\
\hline Bracken $(20-50 \mathrm{~cm})$ & $26.7 \pm 1.1$ & 0.56 & $3.0 \pm 0.8$ & 0.20 & $5.2 \pm 1.0$ & 0.10 \\
\hline Bracken $(50-100 \mathrm{~cm})$ & $26.2 \pm 1.2$ & 0.46 & $9.1 \pm 2.1$ & 0.22 & $7.2 \pm 1.2$ & 0.12 \\
\hline Mosses & $5.0 \pm 0.4$ & 0.23 & $19.9 \pm 1.9$ & 0.79 & $12.3 \pm 0.9$ & 0.61 \\
\hline Bare ground & $3.0 \pm 0.4$ & 0.10 & $14.2 \pm 2.0$ & 0.62 & $2.2 \pm 0.6$ & 0.07 \\
\hline Extracted PC axes & \multicolumn{2}{|c|}{ Mean $( \pm 1$ se $)$} & \multicolumn{2}{|c|}{ Mean $( \pm 1$ se $)$} & \multicolumn{2}{|c|}{ Mean $( \pm 1 \mathrm{se})$} \\
\hline PC1 & \multicolumn{2}{|c|}{$-0.30 \pm 0.05$} & \multicolumn{2}{|c|}{$-0.51 \pm 0.05$} & \multicolumn{2}{|c|}{$-0.74 \pm 0.07$} \\
\hline PC2 & \multicolumn{2}{|c|}{$0.19 \pm 0.04$} & \multicolumn{2}{|c|}{$-1.08 \pm 0.08$} & \multicolumn{2}{|c|}{$-0.14 \pm 0.08$} \\
\hline PC3 & \multicolumn{2}{|c|}{$0.08 \pm 0.03$} & \multicolumn{2}{|c|}{$-0.59 \pm 0.08$} & \multicolumn{2}{|c|}{$0.01 \pm 0.07$} \\
\hline
\end{tabular}


Table 2 Eigenvalues, proportion of variation explained and factor loadings of the first 3 axes extracted by PCA of 9 foraging patch structural habitat measurements

\begin{tabular}{lccc}
\hline & PC1 & PC2 & PC3 \\
\hline Proportion of variance explained & 0.301 & 0.212 & 0.142 \\
Eigenvector & 2.705 & 1.905 & 1.277 \\
$\%$ cover herbaceous vegetation at height $0-20 \mathrm{~cm}$ & -0.19 & $\mathbf{- 0 . 4 8}$ & $\mathbf{0 . 3 8}$ \\
$\%$ cover herbaceous vegetation at height $20-50 \mathrm{~cm}$ & -0.09 & $\mathbf{- 0 . 3 0}$ & $\mathbf{0 . 6 9}$ \\
$\%$ cover grasses at height $0-20 \mathrm{~cm}$ & -0.22 & $\mathbf{0 . 4 8}$ & 0.02 \\
$\%$ cover grasses at height $20-50 \mathrm{~cm}$ & -0.25 & $\mathbf{0 . 4 4}$ & 0.22 \\
$\%$ cover grasses at height $50-100 \mathrm{~cm}$ & -0.15 & $\mathbf{0 . 3 4}$ & $\mathbf{0 . 3 1}$ \\
$\%$ cover bracken at height $0-20 \mathrm{~cm}$ & $\mathbf{0 . 4 5}$ & 0.04 & 0.17 \\
$\%$ cover bracken at height $20-50 \mathrm{~cm}$ & $\mathbf{0 . 5 5}$ & 0.09 & 0.11 \\
$\%$ cover bracken at height $50-100 \mathrm{~cm}$ & $\mathbf{0 . 5 4}$ & 0.05 & 0.07 \\
\hline \% cover mosses at height $0-20 \mathrm{~cm}$ & -0.14 & $\mathbf{0 . 3 6}$ & $\mathbf{- 0 . 4 3}$ \\
\hline
\end{tabular}

573

574

575

576

577

578

579

580

581

582

583

584

585

586

587

588

589

590 Table 3 The fixed and random effects exploring the influence of vegetation structure variables and their 
591 interaction with land management type on forage patch selection in Whinchats from a minimum adequate 592 generalized linear mixed effects model (GLMM, binomial errors) of: 'Patch type' PC1 + PC2 *

593 'management' + PC3 + 'Julian day' + (1 |Study_area/'Patch identity'). The full model was: 'Patch type'

594 PC1 * 'management' + PC2 * 'management' + PC3 * 'management' + 'Julian Day' + (1 |Study_area/'Patch

595 identity'). The interaction terms with PC1 and PC3 were dropped during the model simplification process

596 (see 'statistical analyses'). The reference category is ungrazed. $\mathrm{N}=307$ patches.

597

\begin{tabular}{lcccc}
\hline Fixed effects & Parameter estimate & se & $Z$ & $P$ \\
\hline intercept & -1.37 & 0.29 & -4.70 & $<0.001$ \\
PC1 & -0.51 & 0.056 & -9.12 & $<0.001$ \\
PC2 & -0.45 & 0.087 & -5.10 & $<0.001$ \\
PC3 & -0.31 & 0.058 & -5.34 & $<0.001$ \\
Habitat type (sheep grazed) & 0.48 & 0.26 & 1.88 & 0.060 \\
Habitat type (deer grazed) & 0.58 & 0.42 & 1.38 & 0.17 \\
Habitat type (sheep grazed) & 0.54 & 0.10 & 5.12 & $<0.001$ \\
${ }^{\text {PC2 }}$ & & & & $<0.001$ \\
Habitat type (deer grazed) * & 0.89 & 0.24 & 3.68 & 0.53 \\
PC2 & 0.005 & 0.009 & 0.63 & \\
Julian day & Variance & & & \\
Random effects & 0.030 & & &
\end{tabular}

598

599

600

601

602

603

604

605

606

607

608 


\section{FIGURES}

610

611 Fig. 1 Map of the 5 principal study sites in central and northern Scotland

612

613 Fig. 2 The probability that a sampled patch was used by a foraging bird as a result of the index of bracken 614 cover (PC1; higher scores denote greater bracken cover) in sheep grazed habitats. The raw observed 615 forage (1) or reference (0) values are represented as open circles (jittered for clearer visibility). Solid lines 616 are the predicted relationships, using median observed values for all other parameters, from the model in 617 table 3. The dotted lines represent the 95\% quantiles obtained from $N=1000$ simulation draws from the 618 estimated parameters. Predicted relationships are significant and statistically similar for deer grazed and 619 ungrazed habitats (not illustrated)

620

621 Fig. 3 The probability that a sampled patch was used by a foraging bird as a result of the index for tall 622 non-bracken vegetation (PC3; higher scores denote a greater cover of taller herbaceous vegetation and 623 tall grasses and lower moss cover) in sheep grazed habitats. Refer to Fig. 2 for explanations of trend lines 624 and symbols. Predicted relationships are significant and statistically similar for deer grazed and ungrazed 625 habitats (not illustrated)

627 Fig. 4 The probability that a sampled patch was used by a foraging bird as a result of the index of non628 bracken vegetation (PC2; higher scores denote a greater cover of grass at all height levels, lower cover of 629 herbaceous plants at all height levels and a lower ground cover by moss) in sheep grazed, deer grazed 630 and ungrazed habitats. Refer to Fig. 2 for explanations of trend lines and symbols. Note that the 631 relationship in both grazed habitats is non-significant. 
632 Fig 1.

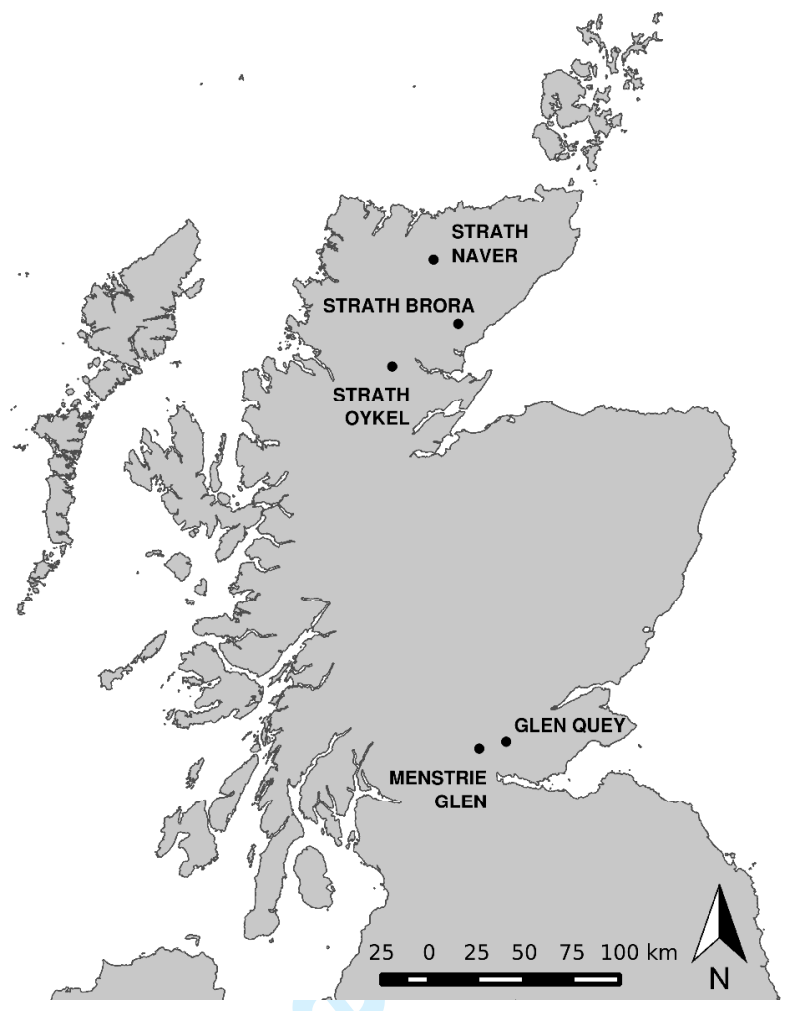


634 Fig. 2

\section{Sheep grazing}

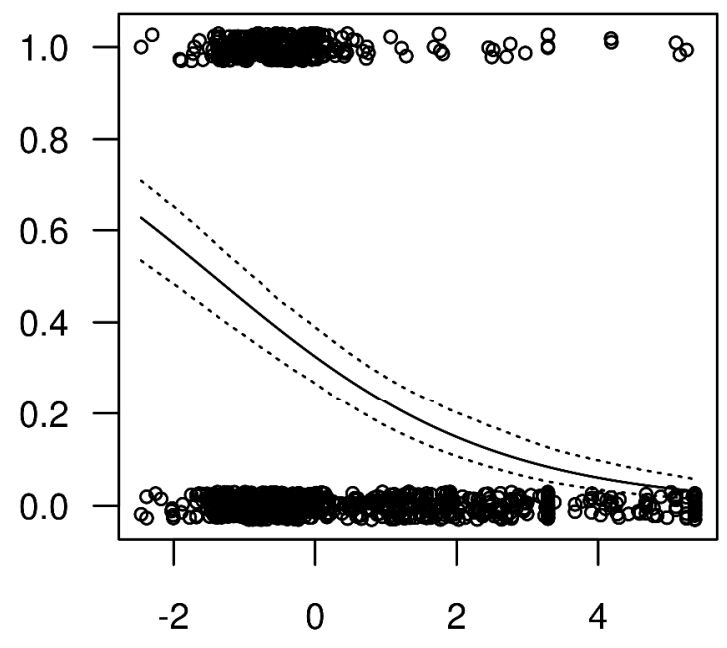

Index of bracken cover (PC1) 
$661 \quad$ Fig. 3

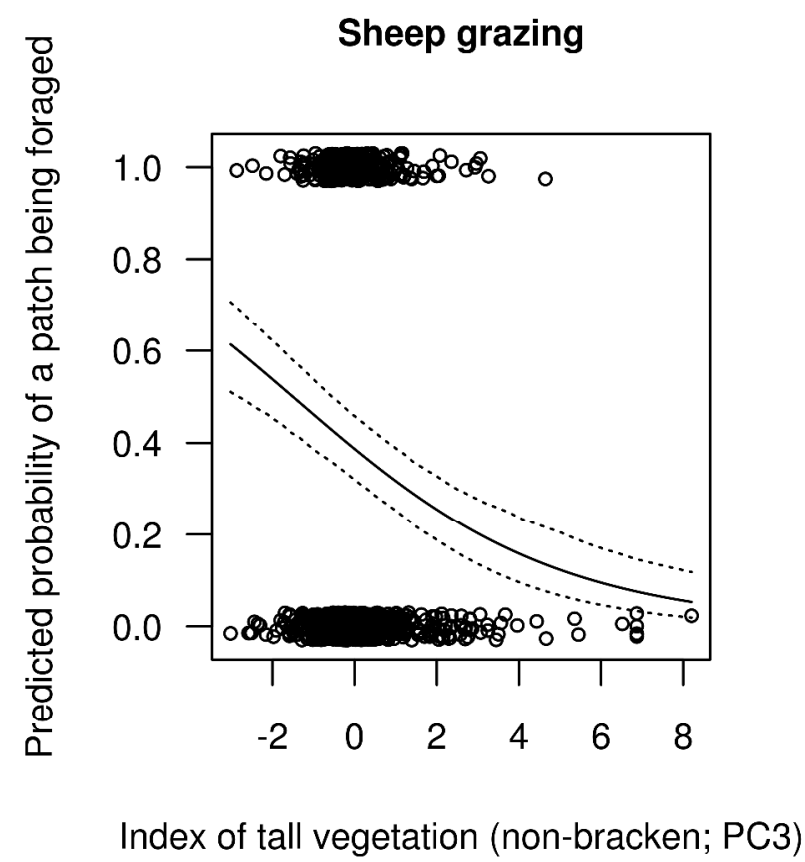


662 Fig. 4
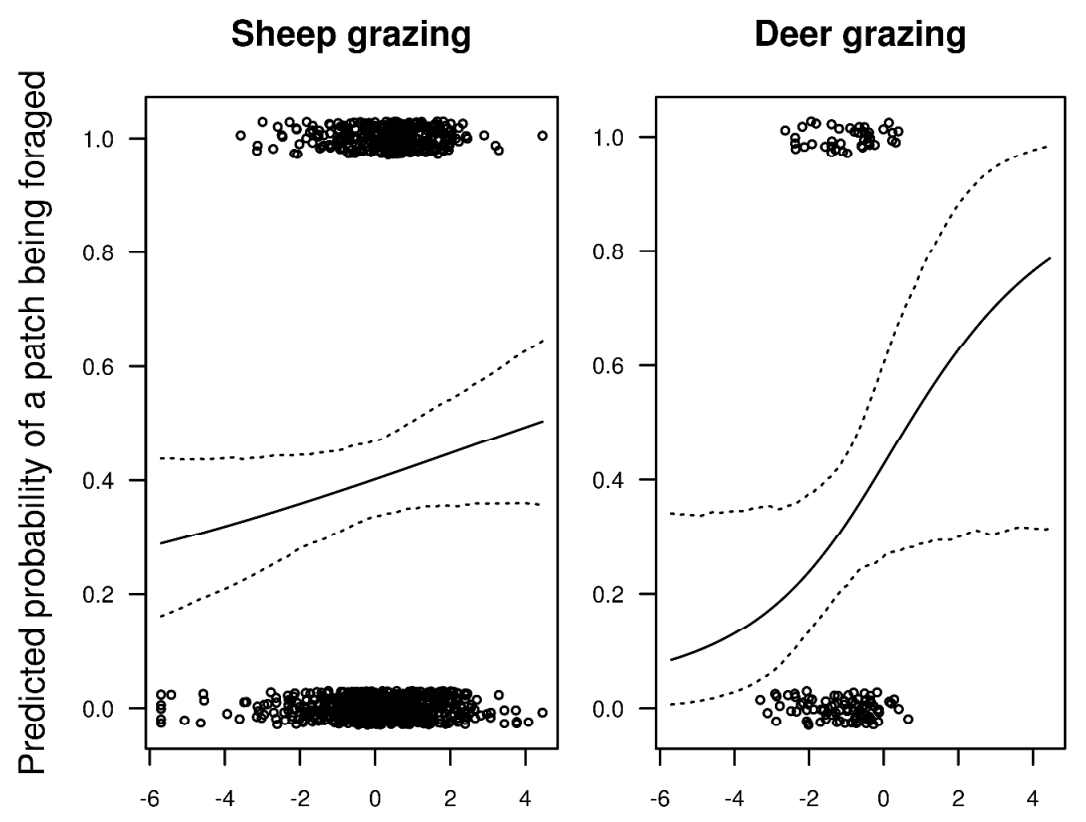

No grazing

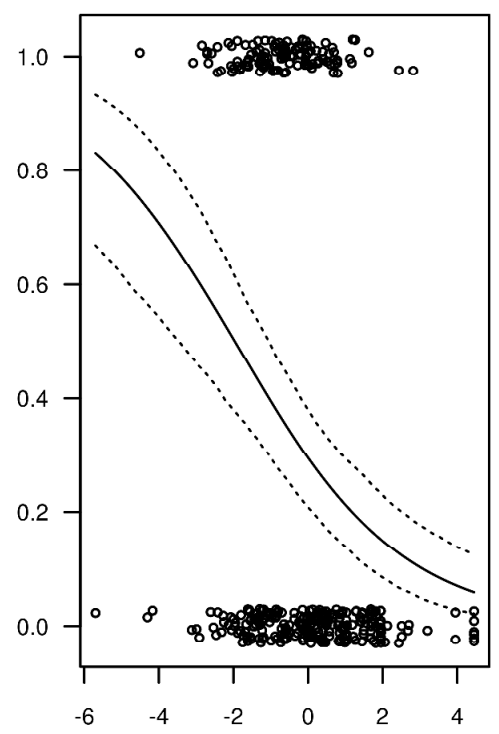

Index of non-bracken vegetation (PC2)

663 